\title{
Aplicações de Nanocarreadores Baseados em Células Animais na Terapia Fotodinâmica em Oncologia
}

\author{
Kelly Winny Rodrigues Miranda'; Camila de Assunção Martins² ; Bárbara de Magalhães Souza \\ Gomes ${ }^{2}$; Jacqueline Andréia Bernardes Leão-Cordeiro ${ }^{3}$; Xisto Sena Passos'; Antonio Márcio \\ Teodoro Cordeiro Silval \\ \kll.miranda@gmail.com
}

1. Universidade Paulista, Goiânia, Goiás, Brasil.

2. Pontifícia Universidade Católica de Goiás, Goiânia, Goiás, Brasil.

3. Universidade Federal de Goiás, Goiânia, Goiás, Brasil.

Histórico do Artigo:

Recebido em: 17 de dezembro de 2019 Aceito em: 25 de maio de $2020 \quad$ Publicado em: 31 de agosto de 2020

Resumo: A terapia fotodinâmica (TFD) é uma técnica bastante promissora, por apresentar alta seletividade, ser minimamente invasiva, com poucos efeitos colaterais. A técnica se baseia em uma reação química ativada por luz, que, para acontecer, conta com três componentes básicos: fonte de luz, oxigênio e um fármaco fotossensibilizante. Apesar de todas as vantagens oferecidas pela TFD, ainda existem alguns aspectos que impedem o uso isolado da TFD no tratamento oncológico, por existir um ambiente de hipóxia no tumor. Além disso, melhorar o direcionamento da entrega do fármaco tem sido um desafio. Este estudo objetivou analisar novas tecnologias empregadas nos nanocarreadores baseados em células animais aplicadas na terapia fotodinâmica. Trata-se de uma revisão integrativa da literatura, em que o levantamento de dados foi feito selecionando artigos publicados entre os anos de 2015 e 2018, utilizando os bancos de dados PubMed, BVS e SciELO. Ao final desse levantamento, 16 artigos foram selecionados, sendo que 10 tratam do uso de hemácias, 4 de células tumorais, 1 de células NK (Natural Killer) e 1 de células endoteliais para o revestimento e transporte de nanopartículas. As tecnologias mostraram-se bastante promissoras para a administração de drogas na terapia fotodinâmica, acrescentando ainda características próprias de cada célula e promovendo a possibilidade de combinação com outras terapias. Conclui-se, portanto, que a utilização de nanocarreadores baseados em células animais, no contexto da terapia fotodinâmica em oncológica, melhora o transporte dos fármacos, o tempo de circulação sanguínea e o aumento da ação fotodinâmica. Neste contexto, o uso de lipossomas se mostrou mais eficaz, com potencial de, juntamente com outras técnicas terapêutica, aumentar a capacidade de supressão tumoral.

Palavras-chave: Nanopartículas biomiméticas, Fotoquimioterapia, Biotecnologia, Câncer.

\section{Applications of Nanocarriers Based on Animal Cells in Photodynamic Therapy in Oncology}

\begin{abstract}
Photodynamic therapy (PDT) is a very promising technique, as it has high selectivity, is minimally invasive, with few side effects. The technique is based on a chemical reaction activated by light, which, to happen, has three basic components: source of light, oxygen and a photosensitizing drug. Despite all the advantages offered by PDT, there are still some aspects that prevent the isolated use of PDT in cancer treatment, as there is a hypoxia environment in the tumor. In addition, improving the direction of drug delivery has been a challenge. This study aimed to analyze new technologies used in nanocarriers based on animal cells applied in photodynamic therapy. This is an integrative literature review, in which data were collected by selecting articles published between the years 2015 and 2018, using the PubMed, BVS and SciEL0 databases. At the end of this survey, 16 articles were selected, 10 of which deal with the use of red cells, 4 of tumor cells, 1 of NK cells and 1 of endothelial cells for the coating and transport of nanoparticles. The technologies have shown to be very promising for the administration of drugs in photodynamic therapy, also adding characteristics of each cell and promoting the possibility of combining with other therapies. It is concluded, therefore, that the use of nanocarriers based on animal cells, in the context of photodynamic therapy in oncology, improves drug transport, blood circulation time and increased photodynamic action. In this context, the use of liposomes proved to be more effective, with the potential to, together with other therapeutic techniques, increase the capacity for tumor suppression.
\end{abstract}

Keywords: Biomimetic nanoparticles, Photochemotherapy, Biotechnology, Cancer. 


\section{Aplicaciones de Nanoportadores Basados en Células de Animales en Terapia Fotodinámica en 0ncología}

Resumen: La terapia fotodinámica (TFD) es una técnica muy prometedora, ya que tiene una alta selectividad, es mínimamente invasiva y tiene pocos efectos secundarios. La técnica se basa en una reacción química activada por la luz que, para suceder, tiene tres componentes básicos: fuente de luz, oxígeno y un fármaco fotosensibilizante. A pesar de todas las ventajas que ofrece la TFD, todavía hay algunos aspectos que impiden el uso aislado de la TFD en el tratamiento del cáncer, ya que existe un ambiente de hipoxia en el tumor. Además, mejorar la dirección del suministro de medicamentos ha sido un desafío. Este estudio tuvo como objetivo analizar nuevas tecnologías utilizadas en nanoportadores basados en células animales aplicadas en terapia fotodinámica. Esta es una revisión integradora de la literatura, en la que se recopilaron datos seleccionando artículos publicados entre los años 2015 y 2018, utilizando las bases de datos PubMed, BVS y SciELO.

Al final de esta encuesta, se seleccionaron 16 artículos, 10 de los cuales tratan sobre el uso de glóbulos rojos, 4 de células tumorales, 1 de células NK (Natural Killer) y l de células endoteliales para el recubrimiento y transporte de nanopartículas. Las tecnologías fueron muy prometedoras para la administración de fármacos en terapia fotodinámica, agregando características de cada célula y promoviendo la posibilidad de combinación con otras terapias. Se concluye, por lo tanto, que el uso de nanoportadores basados en células animales, en el contexto de la terapia fotodinámica en oncología, mejora el transporte de fármacos, el tiempo de circulación sanguínea y una mayor acción fotodinámica. En este contexto, el uso de liposomas demostró ser más efectivo, con el potencial de, junto con otras técnicas terapéuticas, aumentar la capacidad de supresión tumoral.

Palabras clave: Nanopartículas biomiméticas, Fotoquimioterapia, Biotecnología, Cáncer.

\section{INTRODUÇÃo}

De acordo com o Instituto Nacional de Câncer José Alencar Gomes da Silva (INCA), as estimativas para a ocorrência de novos casos de câncer para cada ano do triênio 2020-2022, no Brasil, são de 625 mil (INCA, 2020). 0 tratamento das doenças oncológicas é, na maioria dos casos, bastante complexo, pois as células tumorais podem se adaptar por meio do desenvolvimento de estratégias de sobrevivência (KALIKS et al., 2017).

0 tratamento oncológico consiste principalmente em cirurgia, radioterapia, imunoterapia e quimioterapia. Porém, as aplicações clínicas desses métodos possuem algumas limitações, pois debilitam muito o paciente. A quimioterapia, por exemplo, além de usar fármacos com efeitos adversos bastante prejudiciais ao bem-estar, o uso prolongado pode induzir oncócitos à resistência (KALIKS et al., 2017; SOUZA et al., 2016). Portanto, o desenvolvimento de novas técnicas, mais eficazes e seguras para o tratamento do câncer, é muito importante na luta contra a doença (BRASIL, 2019; WAN et al., 2018).

A Terapia Fotodinâmica (TFD) tem se destacado devido ao seu grande potencial para 0 tratamento do câncer (FAKAYODE et al., 2018). TFD é um método terapêutico que usa a luz com um comprimento de onda adequado e um fármaco atóxico fotossensitizador, que, ao ser exposto à luz, sofre uma reação química, capaz de produzir íons-radicais e oxigênio singlete, que são 
Aplicações de Nanocarreadores Baseados em Células Animais na Terapia Fotodinâmica em Oncologia

altamente citotóxicos (ISSA; MANELA-AZULAY, 2010). A TFD é uma técnica muito promissora, já que é bastante seletiva, pouco invasiva e possui efeitos colaterais mínimos, pois é pouco tóxica para tecidos saudáveis, além de ser simples e barata (FAKAYODE et al., 2018; ISSA; MANELAAZULAY, 2010).

A apoptose celular causada pela TFD ocorre por reação causada pela luz com um composto fotossensibilizador, que em estado triplete se excita eletronicamente e se torna capaz de transferir elétrons, produzindo íons-radicais que tendem a aumentar a carga do oxigênio. Essa excitação eletrônica é capaz também de transformar oxigênio triplete $\left({ }^{3} 0_{2}\right)$ em singlete $\left({ }^{1} 0_{2}\right)$ por um processo de transferência de energia (FARIA, 2017). Isso porque, por meio da distribuição dos elétrons de valência do $\mathrm{O}_{2}$ nos orbitais Px, Py, Pz, é possível gerar dois estados distintos, definidos pela soma dos spins dos elétrons presentes nesses orbitais. Quando a soma é igual a 0, o estado do oxigênio é singlete, quando a soma é +1, o oxigênio é triplete (GARCIA, 2005). Assim, o oxigênio singlete junto com íons-radicais, produzidos na transferência de elétrons, são capazes de induzir a apoptose e/ou necrose celular. Para que isso ocorra, os fotossensitizadores, após sua administração, se acumulam nas organelas e nas membranas celulares e vasculares e, ao entrar em contato com a luz, promovem suas reações degradando as membranas e organelas da célula. Essa destruição promove a liberação de citocinas que desencadeiam reação imunológica que promove a apoptose (GARCIA, 2005).

A luz próxima de infravermelho (NIR, near-infrared) é atualmente a mais utilizada para a execução da TFD, isso devido a sua boa penetração em tecido profundo e baixa autofluorescência (CHEN et al., 2014). Por conta disso, uma série de fármacos absorventes de NIR tem sido estudada. A indocianina verde (ICG, indocyanine green) é um corante sensível a NIR, aprovado pela Agência Federal de Administração de Drogas e Alimentos dos EUA (FDA, Food and Drug Administration) para diagnóstico clínico de imagem, que tem sido uma grande aposta para a TFD e Terapia Fototérmica (PTT, photothermal therapy), devido a seu grande poder de penetração em tecidos, a capacidade de produzir nanopartículas que geram ${ }^{1} 0_{2}$ quando exposta a luz NIR e a geração de energia térmica capaz de destruir células tumorais (DING et al., 2015).

A nanotecnologia desempenha um papel de suma importância na terapia fotodinâmica, pois os nanomateriais têm sido cada vez mais usados nas aplicações biomédicas, como, por exemplo, na ressonância magnética e na terapia gênica (FAKAYODE et al., 2018). Porém, os nanomateriais precisam cumprir critérios de biocompatibilidade para serem usados nas aplicações biomédicas voltadas à TFD, tais como, boa estabilidade biológica, alta absorvidade molar, estabilidade fotofísica e alto índice de toxicidade luz-escuro (MOURA, 2017). A fim de 
prolongar o tempo de circulação sistêmica dos nanocarreadores e fugir da eliminação pelo sistema imunológico, cientistas têm projetado nanocarreadores biomiméticos baseados em membranas celulares (LUBICH et al., 2016; GA0; ZHANG, 2015). Com isso, os nanocarreadores podem ser disfarçados como células e escapar da eliminação, promovendo efeito da permeabilidade e retenção para o direcionamento do tumor (MOURA, 2017; LUBICH et al., 2016).

A busca por novos métodos de tratamento que sejam mais eficientes e menos agressivos tem motivado pesquisadores em todo o mundo. A terapia fotodinâmica, junto com a nanotecnologia, tem sido considerada tecnologia inovadora e com amplas perspectivas de aplicação no tratamento oncológico (WAN et al., 2018).

Sabe-se que hoje nanocarreadores biomiméticos baseados em membranas de células têm ganhado cada vez mais atenção para o transporte de fármacos (LUK; ZHANG, 2015). Pensando nisso, e no potencial que a terapia fotodinâmica pode ter para o tratamento de oncologias, esta revisão teve como guia a seguinte pergunta: Como as novas tecnologias empregadas nos nanocarreadores, camuflados por células animais, podem contribuir para avanços na terapia fotodinâmica? Assim, o presente estudo objetivou analisar novas tecnologias empregadas nos nanocarreadores baseados em células animais aplicadas na terapia fotodinâmica.

\section{METODOLOGIA}

Foi feita uma revisão integrativa da literatura sobre a aplicação da tecnologia de nanocarreadores, baseados em células animais, na terapia fotodinâmica em oncologia. As pesquisas integrativas têm como objetivo a avaliação crítica de evidências encontradas com a reunião sintetizada de resultados de pesquisa sobre um tema em questão, de maneira sistemática e ordenada, aprofundando no tema investigado, a fim de implantar as informações coletadas na prática clínica.

Para a seleção dos artigos foram utilizadas três bases de dados: SciELO (Scientific Electronic Library Online), PubMed, e BVS (Biblioteca Virtual em Saúde). Os critérios de inclusão foram artigos pulicados nos idiomas português e inglês, de 2015 a 2018, que apresentassem sistemas de entregas de drogas usando nanopartículas camufladas por células animais que fossem úteis para a terapia fotodinâmica no tratamento de oncologias. Foram excluídos artigos em outros idiomas que não os considerados, publicados anteriormente ao ano de 2015 e que não respondiam à pergunta norteadora da pesquisa. 0 período escolhido para a coleta de dados (a partir de 2015) objetivou avaliar artigos de publicação recente, evitando assim 
Aplicações de Nanocarreadores Baseados em Células Animais na Terapia Fotodinâmica em Oncologia

selecionar estudos publicados há mais de 5 anos, pois poderiam, pelo tempo transcorrido, apresentar equívocos conceituais e/ou metodologias e teorias ultrapassadas e já modificadas.

0 levantamento de dados ocorreu entre os meses de fevereiro e agosto do ano de 2018, utilizando a combinação dos descritores: Membrana Celular (Cell Membrane), Célula (Celh), Membranas (Membranes), Revestidas com Membranas (Membranes Coated), Revestidas com Membrana Celular (Cell-Membrane Coated), Estrutura Celular (Cellular Structure), Estrutura da Membrana Celular (Cell-Membrane Structure), Biomimética da Membrana Celular (Cell Membrane Biomimetic), Glóbulos Vermelhos Nanoescalados (Nanscaled Red Blood Cells), Glóbulos Vermelhos (Red Blood Cells), Lipossomos (Lipossomes), Entrega de Fármacos (Drug Delivery), Entrega Direcionada (Targeted Delivery), Sistema de Distribuição (Delivery System), Terapia Fotodinâmica (Photodynamic Therapy), Fotoquimioterapia (Photochemotherapy), Fotodinâmica (Photodynamic), Sensível a Luz (Light Sensive), Infravermelho Próximo ao infravermelho (Near-Infrared Irradiation), Neoplasia, Neoplasma, Câncer (Cancer), Tumor, Nanomedicina (Nanomedicine), Nanopartículas (Nanoparticles), Nanocarreadores (Nanocarriers), Tratamento Combinado (Combination Treatment). Os termos foram cruzados como palavra do resumo e título, utilizando as várias possibilidades de agrupamento, com os booleandos "AND"e "OR".

Por meio desse levantamento de dados, inicialmente foram encontrados 78 artigos na BVS e 575 na PubMed, nenhum artigo foi encontrado no SciELO. Destes, 53 artigos foram publicados entre o período de 2015 a 2018 na BVS e 297 na PubMed. Após a leitura dos títulos e resumos, 8 artigos da BVS e 19 artigos PubMed foram escolhidos para serem analisados integralmente, sendo que, 7 artigos tinham duplicidade à BVS e PubMed, resultando, no total de 20 artigos. Após a leitura integral, finalmente 16 artigos foram selecionados para fazer parte desta revisão. Para definir a elegibilidade dos estudos, foi utilizado o método de leitura científica, que se baseia nas seguintes etapas: leitura de reconhecimento geral para aproximação do tema do estudo e leitura seletiva, buscando informações sobre o objetivo do estudo; leitura reflexiva e crítica dos artigos selecionados e escolha dos conteúdos principais relacionados ao tema; e leitura de interpretação dos resultados apresentados nos estudos (visão sintética). Aqueles artigos publicados antes de 2015, em outros idiomas que não o inglês ou 0 português e que não respondiam à pergunta norteadora da pesquisa, foram excluídos da presente revisão.

A análise foi realizada pelo método de análise temática, que tem como principal característica a síntese da linha de raciocínio do autor, ressaltando os achados mais 
importantes, ou seja, aqueles que atendiam os objetivos desta pesquisa, e a contribuições científicas obtidas com cada estudo (SILVA; BORGES, 2017).

\section{RESULTADOS E DISCUSSÃ0}

0 Quadro 1 foi composto por 16 artigos que foram selecionados para esta revisão. Dos 16 artigos, 8 foram encontrados apenas na Base de Dados PubMed, 1 foi encontrado apenas na Biblioteca Virtual da Saúde (BVS) e nenhum foi na SciELO, sendo que, 7 artigos possuíam duplicidade em PubMed e BVS. Os artigos foram selecionados por meio da avaliação sintética.

Quadro 1. Distribuição dos artigos selecionados na revisão integrativa.

\begin{tabular}{|c|c|c|c|}
\hline Citação do artigo & $\begin{array}{l}\text { Tipo de } \\
\text { nanopartículas }\end{array}$ & $\begin{array}{l}\text { Tipo de tumor } \\
\text { que as } \\
\text { nanopartículas } \\
\text { foram testadas }\end{array}$ & Principais conclusões \\
\hline $\begin{array}{l}\text { YU et al. (2018) } \\
\text { Reassembly of 89Zr- } \\
\text { Labeled Cancer Cell } \\
\text { Membranes into } \\
\text { Multicompartment } \\
\text { Membrane-Derived } \\
\text { Liposomes for PET- } \\
\text { Trackable Tumor-Targeted } \\
\text { Theranostics }\end{array}$ & $\begin{array}{l}\text { Lipossomas derivados } \\
\text { de membranas } \\
\text { multicompartimentai } \\
\text { s integrando Tween- } \\
80 \text { em membranas } \\
\text { celulares de } \\
\text { carcinoma mamário } \\
\text { 4Tl. }\end{array}$ & $\begin{array}{l}\text { Carcinoma } \\
\text { mamário (4Tl) }\end{array}$ & $\begin{array}{l}0 \text { método mostrou eficácia no } \\
\text { rastreamento não invasivo, } \\
\text { baixa toxicidade, boa captação } \\
\text { tumoral, direcionamento na } \\
\text { entrega do fármaco, bom efeito } \\
\text { fotodinâmico e destruição } \\
\text { tumoral. }\end{array}$ \\
\hline $\begin{array}{l}\text { REN et al. (2017) } \\
\text { Oxygen Self-enriched } \\
\text { Nanoparticles } \\
\text { Functionalized with } \\
\text { Erythrocyte Membranes } \\
\text { for Long Circulation and } \\
\text { Enhanced Phototherapy }\end{array}$ & $\begin{array}{l}\text { Nanopartículas } \\
\text { biomiméticas de } \\
\text { albumina com ICG e } \\
\text { Perfluorocarbono } \\
\text { auto-enriquecidas } \\
\text { com oxigênio e } \\
\text { camufladas com } \\
\text { membrana de } \\
\text { hemácias. }\end{array}$ & $\begin{array}{l}\text { Câncer de } \\
\text { colorretal (CT- } \\
26)\end{array}$ & $\begin{array}{l}0 \text { método mostrou prolongar o } \\
\text { tempo de circulação sistêmica } \\
\text { das nanopartículas, } \\
\text { acumulação do fármaco no } \\
\text { tumor, e inibição do } \\
\text { crescimento tumoral. Além de } \\
\text { ação fotodinâmica e } \\
\text { fototérmica aumentada. }\end{array}$ \\
\hline $\begin{array}{l}\text { RA0 et al. (2016) } \\
\text { Photocatalytic } \\
\text { Degradation of Cell } \\
\text { Membrane Coatings for } \\
\text { Controlled Drug Release }\end{array}$ & $\begin{array}{l}\text { Nanopartículas de } \\
\text { Tio2 e core-shell } \\
\text { revestida por } \\
\text { membrana de } \\
\text { hemácias. }\end{array}$ & $\begin{array}{l}\text { Câncer de mama } \\
\text { humano (MCF-7) }\end{array}$ & $\begin{array}{l}0 \text { método demonstrou } \\
\text { aumentar a atividade } \\
\text { fotocatalítica, boa distribuição } \\
\text { do fármaco e eficiência em } \\
\text { matar células cancerígenas. }\end{array}$ \\
\hline XUAN et al. (2018) & $\begin{array}{l}\text { Nanopartícula de } \\
\text { sílica magnética }\end{array}$ & Carcinoma & $\begin{array}{l}0 \text { método demonstrou } \\
\text { estabilidade, }\end{array}$ \\
\hline
\end{tabular}


Aplicações de Nanocarreadores Baseados em Células Animais na Terapia Fotodinâmica em Oncologia

\begin{tabular}{|c|c|c|c|}
\hline $\begin{array}{l}\text { Red Blood Cell Membranes } \\
\text { Cloaked Magnetic } \\
\text { Mesoporous Silica } \\
\text { Nanoparticles Applied for } \\
\text { Cancer Therapy }\end{array}$ & $\begin{array}{l}\text { mesoporosa (MMSN) } \\
\text { camuflada com } \\
\text { membrana de } \\
\text { hemácias. }\end{array}$ & mamário (4T1) & $\begin{array}{l}\text { biocompatibilidade, circulação } \\
\text { prolongada e melhoria no } \\
\text { direcionamento das } \\
\text { nanopartículas. }\end{array}$ \\
\hline $\begin{array}{l}\text { SU et al. (2017) } \\
\text { Enhanced Blood } \\
\text { Suspensibility and Laser- } \\
\text { Activated Tumor-specific } \\
\text { Drug Release of } \\
\text { Theranostic Mesoporous } \\
\text { Silica Nanoparticles by } \\
\text { Functionalizing with } \\
\text { Erythrocyte Membranes }\end{array}$ & $\begin{array}{l}\text { Nanopartículas de } \\
\text { sílica mesoporosa } \\
\text { camuflada com } \\
\text { membrana de } \\
\text { hemácia para co- } \\
\text { carregar } \\
\text { doxorrubicina e Ce6. }\end{array}$ & $\begin{array}{l}\text { Carcinoma } \\
\text { mamário (4T1) }\end{array}$ & $\begin{array}{l}0 \text { método mostrou-se capaz de } \\
\text { manter a estabilidade coloidal } \\
\text { de MNSs e impedir a liberação } \\
\text { prematura do fármaco. Além } \\
\text { de suprimir por completo o } \\
\text { crescimento tumoral e inibir a } \\
\text { ocorrência de metástase. }\end{array}$ \\
\hline $\begin{array}{l}\text { XIA et al. (2018) } \\
\text { Cytokine induced killer } \\
\text { cells-assisted delivery of } \\
\text { chlorin e6 mediated self- } \\
\text { assembled gold } \\
\text { nanoclusters to tumors for } \\
\text { imaging and immuno- } \\
\text { photodynamic therapy }\end{array}$ & $\begin{array}{l}\text { Nanopartículas de } \\
\text { ouro em } \\
\text { nanopartículas } \\
\text { estáveis } \\
\text { monodispersas } \\
\text { usando moléculas de } \\
\text { Ce6 } \\
\text { (fotosensibilizador) } \\
\text { transportadas por } \\
\text { células NK. }\end{array}$ & $\begin{array}{l}\text { Câncer gástrico } \\
\text { humano (MGC- } \\
803 \text { ) }\end{array}$ & $\begin{array}{l}\text { A experiência mostrou } \\
\text { potencial na utilização de } \\
\text { células NK no transporte de } \\
\text { GNC-Ce6-Ab para os tecidos } \\
\text { tumorais. }\end{array}$ \\
\hline $\begin{array}{l}\text { LI et al. (2018) } \\
\text { Cell-Membrane Coated } \\
\text { Semiconducting Polymer } \\
\text { Nanoparticles for } \\
\text { Enhanced Multimodal } \\
\text { Cancer Phototheranostics }\end{array}$ & $\begin{array}{l}\text { Nanoagentes } \\
\text { Fototeranósticos } \\
\text { multimodais } \\
\text { revestidos com } \\
\text { membranas celulares } \\
\text { de fibroblastos } \\
\text { ativados. }\end{array}$ & $\begin{array}{l}\text { Fibroblastos } \\
\text { associados ao } \\
\text { câncer }\end{array}$ & $\begin{array}{l}0 \text { método mostrou provocou } \\
\text { acúmulo mais elevado de } \\
\text { nanopartículas nos tecidos do } \\
\text { que os outros métodos } \\
\text { testados. Também contribuiu } \\
\text { para projetar estratégias } \\
\text { terapêuticas de superar } \\
\text { barreiras de entrega no tumor. }\end{array}$ \\
\hline $\begin{array}{l}\text { DING et al. (2015) } \\
\text { Erythrocyte Membrane- } \\
\text { Coated Biomimetic } \\
\text { Nanovectors with } \\
\text { Programmed Delivery and } \\
\text { Near-Infrared Light } \\
\text { Triggering Properties for } \\
\text { Photodynamic Therapy of } \\
\text { Cancer }\end{array}$ & $\begin{array}{l}\text { Nanopartículas } \\
\text { upconversion (UCNP) } \\
\text { com } \\
\text { fotossensibilizadores } \\
\text { incorporados com o } \\
\text { núcleo interno e a } \\
\text { membrana } \\
\text { eritrocitária. }\end{array}$ & Melanoma (B16) & $\begin{array}{l}\text { O revestimento com membrana } \\
\text { de eritrócitos mostrou facilitar } \\
\text { o transporte de oxigênio e } \\
\text { permitiu um melhor } \\
\text { direcionamento seletivo de } \\
\text { células cancerigenas e } \\
\text { orientação precisa para } \\
\text { mitocôndrias. } 0 \text { modelo } \\
\text { melhorou significativamente a } \\
\text { taxa de sobrevivência de } \\
\text { camundongos portadores de } \\
\text { tumor além de quase parar o } \\
\text { crescimento tumoral. }\end{array}$ \\
\hline LI et al. (2018) & $\begin{array}{l}\text { Nanoplataforma } \\
\text { composta com um }\end{array}$ & Carcinoma & $\begin{array}{l}\text { 0 trabalho forneceu uma } \\
\text { estratégia promissora e }\end{array}$ \\
\hline
\end{tabular}




\begin{tabular}{|c|c|c|c|}
\hline $\begin{array}{l}\text { Biomimetic Persistent } \\
\text { Luminescent } \\
\text { Nanoplatform for } \\
\text { AutofluorescenceFree } \\
\text { Metastasis Tracking and } \\
\text { Chemo-photodynamic } \\
\text { Therapy }\end{array}$ & $\begin{array}{l}\text { núcleo de } \\
\text { nanopartículas } \\
\text { luminescente } \\
\text { invólucro de } \\
\text { membrana de célula } \\
\text { cancerígena. }\end{array}$ & mamário (4T1) & $\begin{array}{l}\text { inovadora para projetar } \\
\text { sistemas de entrega de } \\
\text { fármacos de maneira } \\
\text { controlável e precisa para } \\
\text { metástase em terapêutica. }\end{array}$ \\
\hline $\begin{array}{l}\text { PEI et al. (2018) } \\
\text { Light-Activatable Red } \\
\text { Blood Cell Membrane- } \\
\text { Camouflaged Dimeric } \\
\text { Prodrug Nanoparticles for } \\
\text { Synergistic } \\
\text { Photodynamic/Chemother } \\
\text { apy }\end{array}$ & $\begin{array}{l}\text { Nanopartícula } \\
\text { composta de dímero } \\
\text { de paclitaxel e } \\
5,10,15,20- \\
\text { tetrafenilclorina com } \\
\text { invólucro externo a } \\
\text { base de membrana de } \\
\text { eritrócito. }\end{array}$ & $\begin{array}{l}\text { Câncer cervical } \\
\text { (HeLa) }\end{array}$ & $\begin{array}{l}\text { Os resultados mostram que os } \\
\text { revestimentos da membrana } \\
\text { de eritrócitos prolongam o } \\
\text { tempo de circulação sanguínea } \\
\text { e melhora a acumulação em } \\
\text { tumores. }\end{array}$ \\
\hline $\begin{array}{l}\text { WAN et al. (2018) } \\
\text { Nanoscaled red blood cells } \\
\text { facilitate breast cancer } \\
\text { treatment by combining } \\
\text { photothermal/photodyna } \\
\text { mic therapy and } \\
\text { chemotherapy }\end{array}$ & $\begin{array}{l}\text { Nanosistema } \\
\text { biomimético } \\
\text { preparado com } \\
\text { hemácias, capazes de } \\
\text { carregar oxiHb, ICG e } \\
\text { doxorrubicina. }\end{array}$ & $\begin{array}{l}\text { Carcinoma } \\
\text { mamário (4T1) }\end{array}$ & $\begin{array}{l}0 \text { sistema demonstrou } \\
\text { eficiência no transporte de } \\
\text { oxigênio, fotossensibilizante e } \\
\text { fármaco quimioterápico, além } \\
\text { de boa hemocompatibilidade e } \\
\text { biossegurança. }\end{array}$ \\
\hline $\begin{array}{l}\text { GA0 et al. (2017) } \\
\text { Photosensitizer Decorated } \\
\text { Red Blood Cells as an } \\
\text { UltraSensitive Light- } \\
\text { Responsive Drug Delivery } \\
\text { System }\end{array}$ & $\begin{array}{l}\text { Sistema natural de } \\
\text { entrega de fármacos } \\
\text { baseado em } \\
\text { hemácias. } 0 \\
\text { fotossensibilizador } \\
\text { C6e é inserido na } \\
\text { membrana das } \\
\text { hemácias e dentro } \\
\text { delas é inserido } \\
\text { doxorrubicina para } \\
\text { ser transportado pela } \\
\text { célula. }\end{array}$ & $\begin{array}{l}\text { Carcinoma } \\
\text { mamário (4T1) }\end{array}$ & $\begin{array}{l}0 \text { sistema mostrou que o } \\
\text { fotossensibilizante pode deixar } \\
\text { a membrana da célula sensível } \\
\text { a luz sem prejudicar sua } \\
\text { estabilidade no escuro. } 0 \\
\text { transporte de Dox realizado } \\
\text { pela célula pode melhorar o } \\
\text { efeito terapêutico e o sistema } \\
\text { pode potencializar a resposta à } \\
\text { PDT. }\end{array}$ \\
\hline $\begin{array}{l}\text { ZHU et al. (2017) } \\
\text { Erythrocyte membrane- } \\
\text { coated Gold nanocages for } \\
\text { targeted cancer } \\
\text { photothermal and } \\
\text { chemical therapy }\end{array}$ & $\begin{array}{l}\text { Nanocagens de ouro } \\
\text { recobertas com } \\
\text { membrana de } \\
\text { eritrócitos. }\end{array}$ & $\begin{array}{l}\text { Carcinoma } \\
\text { mamário (4Tl) }\end{array}$ & $\begin{array}{l}\text { 0 objeto de estudo mostrou-se } \\
\text { capaz de melhorar o } \\
\text { direcionamento das } \\
\text { nanopartículas às células 4T1, } \\
\text { além disso foi capaz de causar } \\
\text { mortalidade em massa das } \\
\text { células cancerígenas. }\end{array}$ \\
\hline $\begin{array}{l}\text { SHENG et al. (2016) } \\
\text { Encapsulation of } \\
\text { indocyanine green into cell } \\
\text { membrane capsules for }\end{array}$ & $\begin{array}{l}\text { Cápsulas de } \\
\text { membrana de células } \\
\text { endoteliais foram } \\
\text { usadas para } \\
\text { encapsular ICG e }\end{array}$ & $\begin{array}{l}\text { Hepatocarcinom } \\
\text { a (HepG2) }\end{array}$ & $\begin{array}{l}\text { 0 método mostrou-se capaz de } \\
\text { aumentar a retenção de ICG } \\
\text { intratumoral quando } \\
\text { comparado com ICG livre o que } \\
\text { consequentemente levou a }\end{array}$ \\
\hline
\end{tabular}


Aplicações de Nanocarreadores Baseados em Células Animais na Terapia Fotodinâmica em Oncologia

\begin{tabular}{|c|c|c|c|}
\hline $\begin{array}{l}\text { photothermal cancer } \\
\text { therapy }\end{array}$ & doxorrubicina. & & $\begin{array}{l}\text { uma melhora no efeito } \\
\text { fototerápico. }\end{array}$ \\
\hline $\begin{array}{l}\text { CHEN et al. (2016) } \\
\text { Cancer Cell Membrane- } \\
\text { Biomimetic Nanoparticles } \\
\text { for HomologousTargeting } \\
\text { Dual-Modal Imaging and } \\
\text { Photothermal Therapy }\end{array}$ & $\begin{array}{l}\text { Sistema de } \\
\text { nanopartículas } \\
\text { biomimética e } \\
\text { teranósticas de ICG } \\
\text { encapsulada por } \\
\text { membranas de } \\
\text { células cancerígenas }\end{array}$ & $\begin{array}{l}\text { Câncer de mama } \\
(\mathrm{MCF}-7)\end{array}$ & $\begin{array}{l}0 \text { sistema demonstrou que as } \\
\text { moléculas de adesão celular na } \\
\text { superfície das nanopartículas } \\
\text { conseguiram causar } \\
\text { acumulação tumoral. }\end{array}$ \\
\hline $\begin{array}{l}\text { LU0 et al. (2016) } \\
\text { Self-Monitoring Artificial } \\
\text { Red Cells with Sufficient } \\
\text { Oxygen Supply for } \\
\text { Enhanced Photodynamic } \\
\text { Therapy }\end{array}$ & $\begin{array}{l}\text { Glóbulos vermelhos } \\
\text { artificiais carregando } \\
\text { hemoglobina e ICG }\end{array}$ & $\begin{array}{l}\text { Câncer de mama } \\
(\mathrm{MCF}-7)\end{array}$ & $\begin{array}{l}\text { A nanoplataforma mostrou-se } \\
\text { eficiente no fornecimento de } \\
\text { oxigênio, no monitoramento } \\
\text { por imagem de fotoacústica e } \\
\text { na biodistribuição, resultando } \\
\text { na supressão completa do } \\
\text { tumor. }\end{array}$ \\
\hline
\end{tabular}

Fonte: autor (2020).

Da análise do conteúdo das publicações, surgiram as seguintes proposições temáticas: (I) prolongamento na circulação sistêmica; (II) direcionamento específico; (III) estabilidade na administração de drogas fotossensibilizantes e outras; (IV) sistemas teranósticos. Tais conteúdos foram identificados com a avaliação crítica dos conteúdos de cada artigo.

Nos últimos anos, o uso de nanopartículas para administração de drogas tem ganhado cada vez mais espaço, isso ocorre porque nanopartículas produzidas por materiais inorgânicos têm uso limitado devido ao seu alto índice de depuração e seu potencial de toxicidade. Por essa razão, o uso de células como base para a produção de nanopartículas tem ganhado cada vez mais espaço (LUK; ZHANG, 2015; SHENG et al., 2016). Dentre as vantagens oferecidas pelos avanços na nanoengenharia das biomembranas tem-se a biocompatibilidade, a baixa toxicidade e a capacidade de escapar no retículo endotelial (LUK; ZHANG, 2015; YU et al., 2018).

0 uso de membrana de célula de mamífero para revestir ICG e doxorrubicina (quimioterápico) foi retratado por Sheng et al. (2016) que oferece uma proposta de terapias combinadas (TFD e quimioterapia). Nesse estudo, o autor relata que, durante o uso de nanocarreadores de membrana celular, a retenção intratumoral de indocianina verde e doxorrubicina mostrou-se aumentada, quando comparada à administração dessas substâncias sem o uso de nanocarreadores (SHENG et al., 2016).

Muitos estudos sobre nanocarreadores biomiméticos aplicados à terapia fotodinâmica propõe 0 uso de eritrócitos. Isso se dá porque, além da biocompatibilidade e da capacidade de escapar do sistema imunológico, os eritrócitos são transportadores naturais de oxigênio, e o 
transporte de oxigênio pode potencializar os efeitos da terapia fotodinâmica (WAN et al., 2018; REN et al., 2017). 0 uso de membrana de eritrócitos também tem sido sugerido para dar funcionalidade às nanopartículas de sílica mesoporosas, que juntas têm a capacidade de melhorar a estabilidade coloidal e impedir vazamentos (DING et al., 2015; RA0 et al., 2016).

Alguns autores descrevem o uso de nanocarreadores baseados em eritrócitos para combinar a terapia fotodinâmica e outras, como, a terapia fototérmica e a quimioterapia. Isso porque a estabilidade oferecida por esse tipo de revestimento capacita não só o transporte de fotossensibilizantes, mas também de outras substâncias (WAN et al., 2018; RA0 et al., 2016). Mas a combinação da terapia fotodinâmica com outras terapias não é exclusiva de nanocarreadores baseados em hemácias, nanocarreadores revestidos com membranas de oncócitos também se mostraram eficazes nesse aspecto (YU et al., 2018). Além das terapias combinadas, os métodos que usam membranas de oncócitos têm se destacado pela alta capacidade de direcionamento. Isso graças a algumas proteínas expressas nas membranas dessas células que possuem capacidade de ligação homóloga.

0 fotossensibilisador mais usado entre os autores que adotam a terapia fotodinâmica é o ICG, ele é um corante sensível a luz, usado nos EUA, para diagnóstico por imagem. Essa característica possibilita o desenvolvimento de sistemas teranósticos que permitem o monitoramento das nanopartículas através do diagnóstico por imagem (RA0 et al., 2016).

\section{CONCLUSÃO}

0 uso de células para encapsular nanopartículas mostrou-se eficaz para participar de diversos tipos diferentes de sistemas que fazem a distribuição de drogas usadas na terapia fotodinâmica. Quando comparados com os fotossensibilizadores sozinhos, todos os métodos analisados mostraram eficiência, potencializando a técnica e acrescentando características particulares de cada um. Os lipossomas, produzidos a partir de membranas de hemácias, foram o tipo de tecnologia mais estudado e com melhores resultados, quando comparados com os outros tipos de nanocarreadores, com resultados mais eficazes nos seguintes aspectos: transporte dos fármacos, tempo de circulação sanguínea e aumento da ação fotodinâmica.

Ainda existe carência de testes clínicos que comprovem a eficácia dos métodos em seres humanos. A maioria das pesquisas envolve carcinoma mamário, com poucos os estudos de outros tipos de câncer. Apesar de já possuírem boa biocompatibilidade, estabilidade, direcionamento tumoral, entre outros benefícios, as técnicas parecem ser apenas protótipos do 
Aplicações de Nanocarreadores Baseados em Células Animais na Terapia Fotodinâmica em Oncologia

grande passo que a biotecnologia e a bioengenharia estão propondo para o futuro da administração de fármacos no tratamento de doenças oncológicas.

\section{REFERÊNCIAS BIBLIOGRÁFICAS}

BRASIL. Manual técnico operacional SIA/SUS - Sistema de Informações Ambulatoriais: MS, 2010.

CHEN, Q.; LIANG, C.; WANG, C.; LIU, Z. An imagable and photothermal "abraxane-like" nanodrug for combination cancer therapy to treat subcutaneous and metastatic breast tumors. Advanced Materials, Weinheim, v.27, n. 5, p. 903-910, 2014.

CHEN, Z.; ZHA0, P.; LU0, Z.; ZHENG, M.; TIAN, H.; GONG, P.; GAO, G.; PAN, H.; LIU, L.; MA, A.; CUI, H.; MA, Y.; CAI, L. Cancer cell membrane-biomimetic nanoparticles for homologous-targeting dual-modal imaging and photothermal therapy. ACS Nano, Washington, v.10, n.11, p.10049-10057, 2016.

DING, H.; LV, Y.; NI, D.; WANG, J.; TIAN, Z.; WEI, W.; MA G. Erythrocyte membrane-coated NIR-triggered biomimetic nanovectors with programmed delivery for photodynamic therapy of cancer. Nanoscale, Pequim, v.7; n.21, p.9806$9815,2015$.

FAKAYODE, 0. J.; TSOLEKILE, N.; SONGCA S. P.; OLUWAFEMI, O. S. Applications of functionalized nanomaterials in photodynamic therapy. Biophysical Reviews, Johannesburg, v.10, n.1, p. 49-67, 2018.

FARIA, C. M. G. Distribuições de limiar de dose e suas causas e consequências em terapia fotodinâmica. 2017. Dissertação (Mestrado em Física) - Universidade de São Paulo, São Carlos.

GA0, G.; ZHANG, L. Coating nanoparticles with cell membranes for targeted drug delivery. Journal of Drug Targeting, Londres, v.23, n.7-8, p.619-26, 2015.

GA0, M.; HU, A.; SUN, X.; WANG, C.; DONG, Z.; FENG, L.; LIU, Z. Photosensitizer decorated red blood cells as an ultrasensitive light-responsive drug delivery system. ACS Applied Materials \& Interfaces, Washington, v.9, n.7, p.5855-5863, 2017.

GARCIA, F. Formação de oxigênio singlete por fagócitos. 2005. Dissertação (Mestrado em Bioquímica) - Universidade de São Paulo (Instituto de Química), São Paulo.

INCA; MS. Estimativa 2020: incidência de câncer no Brasil. Rio de Janeiro: INCA, 2020.

ISSA, M. C. A.; MANELA-AZULAY, M. Terapia fotodinâmica: uma revisão da literatura e documentação de imagens. Anais Brasileiros de Dermatologia, Rio de Janeiro, v.85, n.04, p.501-211, 2010.

KALIKS, R. A.; MATOS, T. F.; SILVA, V. A.; BARROS, L. H. C. Diferenças no tratamento sistêmico do câncer no Brasil: meu SUS é diferente do teu SUS. Brazilian Journal Of 0ncology, São Paulo, v.13, n.44, p.1-12, 2017.

LI, J.; ZHEN, X.; LYU, Y.; JIANG, Y.; HUANG, J.; PU, K. Cell membrane coated semiconducting polymer nanoparticles for enhanced multimodal cancer phototheranostics. ACS Nano, Washington, v.12, n.8, p.8520-8530, 2018.

LI, Y. J.; YANG, C. X.; YAN, X. P. Biomimetic persistent luminescent nanoplatform for autofluorescence-free metastasis tracking and chemophotodynamic therapy. Analytical Chemistry, Washington, v.90, n.6, p.4188-4195, 2018.

LUBICH, C.; ALLACHER, P.; DE LA ROSA, M.; BAUER, A.; PRENNINGER, T.; HORLING, F. M.; SIEKMANN, J.; OLDENBURG, J.; SCHEIFLINGER, F.; REIPERT, B. M. The mystery of antibodies against polyethylene glycol (PEG) - what do we know? Pharmaceutical Research, Vienna, v.33, n.9, p.2239-2249, 2016.

LUK, B. T.; ZHANG L. Cell membrane-camouflaged nanoparticles for drug delivery. Journal Control Release, California, v.220, p.600-607, 2015. 
LU0, Z;; ZHENG, M.; ZHA0, P.; CHEN, Z;; SIU, F.; GONG, P.; GA0, G.; SHENG, Z.; ZHENG, C.; MA, Y.; CAI, L. Self-monitoring artificial red cells with sufficient oxygen supply for enhanced photodynamic therapy. Scientific Reports, China, 6:23393, 2016.

MOURA, L. D. Tratamento de câncer de mama utilizando terapia fotodinâmica com nanoemulsões de Ftalocianina de cloro alumínio. 2017. Dissertação (Mestrado em Nanociência e Nanobiotecnologia) - Instituto De Ciências Biológicas - UnB, Brasília.

PEI, Q.; HU, X.; ZHENG, X.; LIU, S.; LI, Y.; JING, X.; XIE, Z. Light-activatable red blood cell membrane-camouflaged dimeric prodrug nanoparticles for synergistic photodynamic / chemotherapy. ACS Nano, Washington, v.12, n.2, p.1630-1641, 2018.

RA0, L.; MENG, Q. F.; HUANG, Q.; LIU, P.; BU, L. L.; KONDAMAREDDY, K. K.; GUO, S. S.; LIU, W.; ZHA0, X. Z. Photocatalytic degradation of cell membrane coatings for controlled drug release. Advanced Healthcare Materials, China, v.5, n.12, p.1420-7, 2016.

REN, H.; LIU, J.; LI, Y.; WANG, H.; GE, S.; YUAN, A.; HU, Y.; WU, J. Oxygen self-enriched nanoparticles functionalized with erythrocyte membranes for long circulation and enhanced phototherapy. Acta Biomaterialia, China, v. 59, p. 269-282, 2017.

SHENG, G.; CHEN, Y.; HAN, L.; HUANG, Y.; LIU, X.; LI, L.; MA0, Z. Encapsulation of indocyanine green into cell membrane capsules for photothermal cancer therapy. Acta Biomaterialia, China, v.45, p.251-261, 2016.

SILVA, C. C.; BORGES, F. T. Análise Temática Dialógica como método de análise de dados verbais em pesquisas qualitativas. Linhas Críticas, Brasília, v.23, n.51, p.245-267, 2017.

SOUZA, K. A.; SOUZA, S. R.; TOCANTINS, F. R.; FREITAS, T. F.; PACHECO, P. Q. C. 0 itinerário terapêutico do paciente em tratamento oncológico: implicações para a prática de enfermagem. Cienc Cuid Saude, Maringá, v.15, n.2, p.259-267, 2016.

SU, J.; SUN, H.; MENG, Q.; ZHANG, P.; YIN, Q.; LI, Y. Enhanced blood suspensibility and laser-activated tumor-specific drug release of theranostic mesoporous silica nanoparticles by functionalizing with erythrocyte membranes. Theranostics, China, v.7, n.3, p.523-537, 2017.

WAN, G.; CHEN, B.; LI, L.; WANG, D.; SHI, S.; ZHANG, T.; WANG, Y.; ZHANG, L.; WANG, Y. Nanoscaled red blood cells facilitate breast cancer treatment by combining photothermal/photodynamic therapy and chemotherapy. Biomaterials, China, v.155, p.25-40, 2018.

XIA, F.; HOU, W.; LIU, Y.; WANG, W.; HAN, Y.; YANG, M.; ZHI, X.; LI, C.; QI, D.; LI, T.; MARTINEZ DE LA FUENTE, J.; ZHANG, C.; SONG, J.; CUI, D. Cytokine induced killer cells-assisted delivery of chlorin e6 mediated self-assembled gold nanoclusters to tumors for imaging and immuno-photodynamic therapy. Biomaterials, China, v.170, p.1-11, 2018.

XUAN, M.; SHA0, J.; ZHA0, J.; LI, Q.; DAI, L.; LI, J. Red blood cell membranes cloaked magnetic mesoporous silica nanoparticles applied for cancer therapy. Angew Chem Int Ed Engl, China, v.57, n.21, p.6049-6053, 2018.

YU, B.; GOEL, S.; NI, D.; ELLISON, P. A.; SIAMOF, C. M.; JIANG, D.; CHENG, L.; KANG, L.; YU, F.; LIU, Z.; BARNHART, T. E.; HE, Q.; ZHANG, H.; CAI, W. Reassembly of ${ }^{89} \mathrm{Zr}$-labeled cancer cell membranes into multicompartment membrane-derived liposomes for PET-trackable tumor-targeted theranostics. Advanced Materials, China, v.30, n.13, 2018.

ZHU, D. M.; XIE, W.; XIAO, Y. S.; SU0, M.; ZAN, M. H.; LIAO, Q. Q.; HU, X. J.; CHEN, L. B.; CHEN, B.; WU, W.; JI, L. W.; HUANG, H.; GUO, S. S.; ZHA0, X. Z.; LIU, Q. Y.; LIU, W. Erythrocyte membrane-coated gold nanocages for targeted cancer photothermal and chemical therapy. Nanotechnology, China, v. 29, n. 8, 2017. 